\title{
UNA COPA DRAG. 27 CON GRAFITOS PROCEDENTE DE HUETE (CUENCA)
}

\author{
MARÍA FRANCIA GALIANA \\ Universidad de Alicante \\ MARÍA LUISA RAMOS SÁINZ \\ Universidad Autónoma de Madrid
}

\begin{abstract}
Presentamos una copa Drag. 27 cuyas particularidades en cuanto a tamaño, grafitos y sello de alfarero la hacen destacable dentro del conjunto de la Terra Sigillata Hispanica.

Nous présentons une coupe Drag. 27 dont les particularités, telles que grandeur, graphites et marque de potier, font d'elle une pièce remarquable pour l'étude de la Terra Sigillata Hispanica.
\end{abstract}

El hallazgo de esta pieza excepcional en la campaña de excavaciones de 1986 en el Cerro de Álvar Fáñez (Huete, Cuenca), procedente de un estrato con restos de carácter arquitectónico, mereció nuestra atención desde el momento de su descubrimiento, lo que nos ha llevado a la presente publicación.

En Huete, los hallazgos de cerámica campaniense y monedas ibéricas de la ceca de Arse, Bílbilis, Titiakos y Sekaisa, cuya cronología más alta es del 133 a. C., así como monedas romanas republicanas fechadas a partir del 105 a. C. hasta época de Augusto (DURÁN, 1987), documentan un proceso de romanización temprano en los pobladores olcades. Este fenómeno pudo haber tenido uno de sus motivos en la presencia de minas de lapis specularis (selenita). La importancia de la zona se tes-

* Agradecemos al Prof. Manuel Bendala Galán, director de las excavaciones arqueológicas del Cerro de Álvar Fáñez, las máximas facilidades para la documentación y publicación de la pieza antes que se hayan dado a conocer los resultados de las excavaciones. Asimismo, nos encontramos en deuda con el Prof. Lorenzo Abad Casal, por sus valiosas sugerencias en la identificación del retrato femenino, y con el Prof. Juan Manuel Abascal Palazón, por su asesoramiento en la parte epigráfica. timonia con el paso de la calzada romana republicana que unía Segontia con Villas Viejas, pasando por Carrascosa del Campo, la cual venía a empalmar con el trazado Complutum-Cartago Nova recogido en el Ravenate (ROLDÁN, 1975, 129, Rav. IV, $44[313,8-14])$, y que posteriormente, en época altoimperial, continúa existiendo, pero cambiando el trazado de la vía, que desde Huete, pasando por Alcázar y Rosalén, llegaba a Segóbriga en lugar de Villas Viejas (PALOMERO, 1983, 256-257).

La copa Drag. 27 objeto de nuestro estudio resulta interesante por su gran tamaño (diámetro boca: $20 \mathrm{~cm}$.; diámetros base: 7,5 cm.; altura: 9 $\mathrm{cm}$.). Éste es equiparable únicamente a otro ejemplar proveniente de los talleres de Tritium Magallum, con un diámetro de boca de $19,6 \mathrm{~cm}$. (MAYET, 1984, pl. LXIII: 88). Presenta borde recto de labio redondeado, cuerpo con dos cuartos de círculo, el superior más corto y de curvatura poco pronunciada, pie anular de sección triangular con acanaladura en su cara inferior y el fondo exterior con moldura. Estas características formales se asemejan a una copa también procedente de Tricio y se engloban en el grupo $3 .^{\circ}$ de la forma 27 diferenciado por 


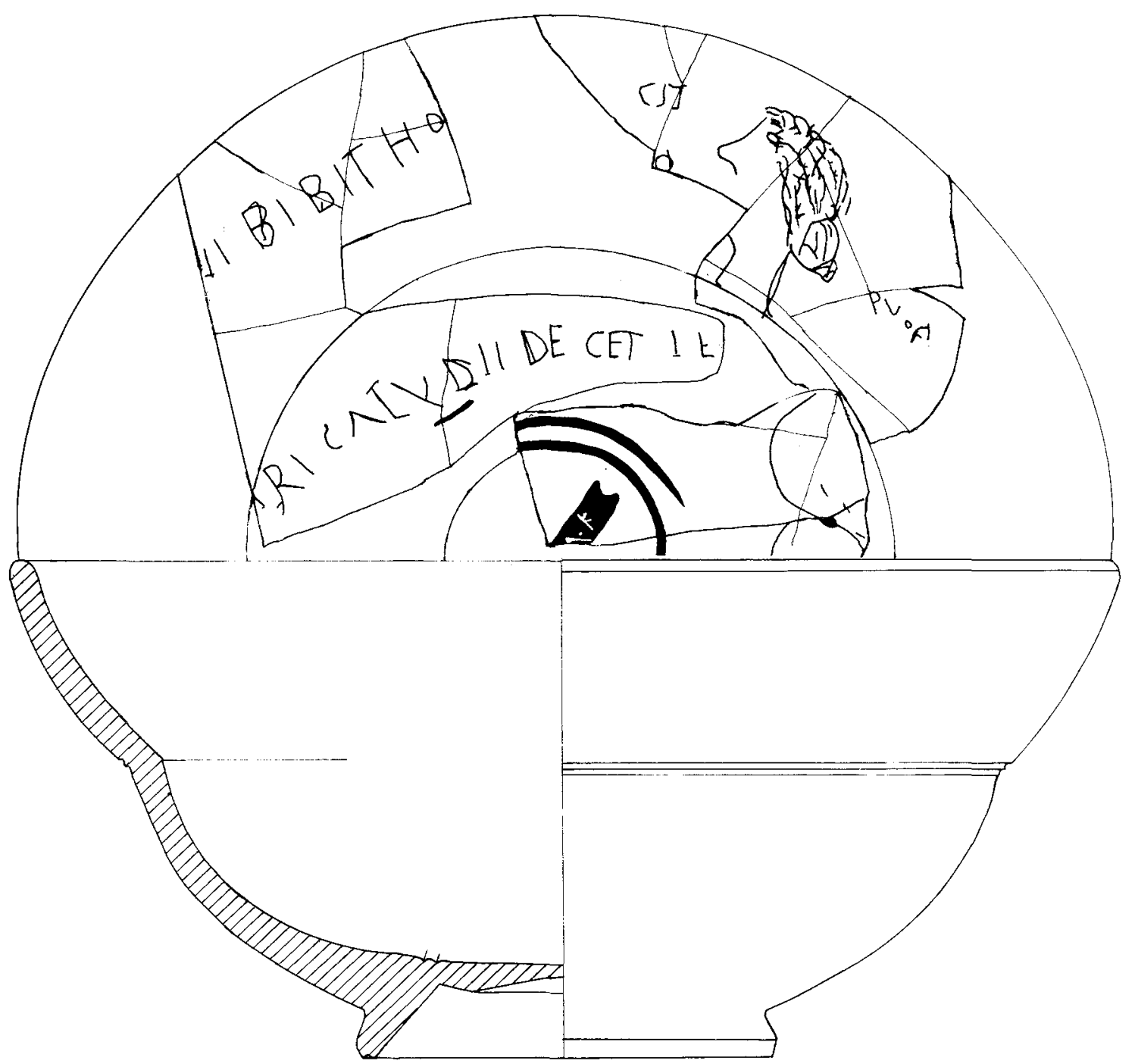

Copa Drag. 27 con grafitos hallada en el Cerro de Alvar Fáñez (Huete, Cuenca) durante la Campaña de Excavaciones de 1986.

F. Mayet (1984, 72, pl. LXV: 103). La pasta es granulosa, con desgrasante fino de tipo calizo blanco y de color rojo inglés o R-20 (CAILLEUX, s/a.). El barniz, mate, de color rosa-anaranjado o M-25 (CAILLEUS, s/a.), es de muy mala calidad y se desprende con facilidad.

La cronología de esta forma se establece unánimemente a partir de mediados del siglo I d. C., pero el final de su producción es polémico, ya que, por una parte, para M. ${ }^{a}$ A. Mezqueriz $(1961,60)$ vendría a ser en los comienzos del siglo IV d. C., basándose para ello en su aparición en el estrato III del Sector E de Pompaelo, y, por otra, para F. Mayet
$(1984,73)$ no se podría precisar por la falta de estudios estratigráficos de los siglos II y III d. C.

La marca de alfarero presenta una cartela de forma rectangular con los extremos bífidos circunscrita por una espiral simple incisa. Sólo se conserva la parte final del sigillum. En ella se lee lo que queda de una $A$, una probable interpunción y una $F$ mal hecha. La primera letra puede corresponder al nombre del alfarero y la segunda a la abreviatura de FECIT. De este modo es posible hacer una transcripción: [ ] A. F(ecit).

Aunque no podemos precisar con exactitud a qué alfarero pertenece, las características formales de 
nuestra copa, así como la localización en Tricio de un officinator cuyo nombre es IVMA y que utiliza una gran variedad de sellos, entre ellos el de IVM.F -IVM(a). F(ecit) - (GARABITO, 1978, 299 y 301; fig. 68: 56 y 59) en una Drag. 27, parecen apuntar la posibilidad de que se tratase de dicho artesano, el cual tendría una producción alfarera a gran escala, abasteciendo a zonas tan alejadas como Banasa, Sala, Lixus (Marruecos), Tarragona, Cástulo, Iruña, Cabriana y Belo (GARABITO, 1978, 301). Apoyándose en las excavaciones de la necrópolis de Sala (Marruecos), J. Boubé $(1968-72,112)$ fecha la producción de ICMA en la segunda mitad del siglo I d. C. Sin embargo, no cabe descartar que nuestra copa procediera de un alfar local, fenómeno que se ha podido constatar durante el Alto Imperio en Tiermes y quizá también en Uxama, donde se conoce un único molde (SÁNCHEZ-LAFUENTE, 1985, 93).

El vaso presenta dos tipos de grafitos: unos son caracteres gráficos que ocupan la pared interna del vaso y se disponen en dos líneas, la primera ubicada en el cuarto de círculo superior y la segunda en el inferior. Otros presentan dibujos: una cabeza femenina de perfil en la que destaca una nariz recta y prominente, el ojo almendrado y un peinado recogido en un moño bajo - semejante al que luce Livia, esposa de Augusto, por lo que podría tratarse de una perduración, ya que nuestra pieza es cronológicamente más moderna-, que se encuentra situada al final de la primera línea de letras y ocupa el cuarto de círculo superior; una línea recta, que se inicia en el borde del sigillum y termina en el cuarto de círculo inferior, rematada por dos círculos tangentes.

Hemos realizado la siguiente transcripción:

1. ${ }^{a}$ LÍNEA: [.... (c) VI BIBIT HO(neste?) [....] CIT (cabeza femenina) QV(inti). FI(lia)

2. ${ }^{a}$ LÍNEA: [....] IRI CAT <I $>$ LLI DECET IL(lo) $[\ldots .$.

\section{L2: CATVLLI}

Traducción: A quien bebe con moderación le sienta bien [ ] del [ ] vaso. Lo dice [ ] hija de Quinto.

De la lectura de los grafitos se desprende que la copa, de uso cotidiano, fue escrita de forma arbitraria por una joven que al utilizar el punzón sobre una superficie tan dura no podía controlar los trazos, apareciendo algunos de ellos desfigurados, como es el caso de la primera «B» de BIBIT, que no fue realizada de un solo trazo; la $\langle\mathrm{F}\rangle$ y la $\langle\mathrm{I}\rangle$ de FI(lia), que aparecen enlazadas; la primera «I» $\mathrm{y}$ «L» de CAT<I>LLI cuya grafía es confusa, y, por último, la «L» de IL(lo), que muestra un trazo suplementario.

\section{BIBLIOGRAFÍA}

BOUBÉ, J. 1968-72: «Les fouilles de la nécropole de Sala et la chronologie de la Terra Sigillata Hispanique», Bulletin d'Archéologie Marocaine, VIII.

CAILLEUS, A. S/a.: Notice sur le code des couleurs des sols, edt. Boubé.

DURÁN CABELLO, R. 1987: Monedas halladas en superficie en el Cerro de Álvar Fáñez (Huete, Cuenca), en prensa.

GARABITO GÓMEZ, T. 1978: Los alfares romanos riojangos. Producción y comercialización, Bibliotheca Praehistorica Hispana, XVI, Madrid.

MAYET, F. 1984: Les céramiques sigillées hispaniques, París. MEZQUIRIZ DE CATALÁN, M. ${ }^{a}$ A. 1961: Terra Sigillata Hipanica, Valencia.

PALOMERO PLAZA, S. 1983: «Las vías romanas de Segóbriga y su contexto en las vías romanas de la actual provincia de Cuenca», Homenaje a Martín Almagro Basch, III.

ROLDÁN HERVÁS, J. M. 1975: Itinera Hispana, ValladolidGranada.

SÁNCHEZ-LAFUENTE PÉREZ, J. 1985: Comercio de cerámicas romanas en Valeria, Arqueología Conquense, VII, Cuenca. 